\title{
Perfil social e ideologia partidária: uma análise do RECRUTAMENTO DOS CANDidATOS A VEREAdor EM CURITIBA (2012) ${ }^{1}$
}

\author{
Bruno Fernando da SiLVA ${ }^{2}$ \\ BRUNA TAYS SiLVA ${ }^{3}$
}

\section{Resumo}

Este estudo tem por objetivo investigar o papel desempenhado pela ideologia na composição social dos candidatos que disputaram uma vaga à Câmara Municipal de Curitiba, nas eleições de 2012. Para tanto, analisa-se informações declaradas pelos candidatos ao Tribunal Superior Eleitoral, como ocupação, patrimônio, escolaridade e sexo. A hipótese é que os partidos encontram dificuldades em montar suas listas de candidatos em eleições locais e que isto produz uma maior heterogeneidade no perfil social deles, comparado aos achados em âmbito federal. Os dados indicam que a eleição municipal tem uma dinâmica distinta da federal, sendo aquela mais aberta a candidatos populares, com menor nível de escolaridade e com ocupações não-tradicionais.

Palavras-chave: Recrutamento político. Perfil social. Ideologia. Eleições 2012.

\footnotetext{
1 Agradecemos aos pareceristas anônimos desta revista pelas valorosas contribuições feitas a este trabalho.

2 Mestrando em Ciência Política pela Universidade Federal do Paraná (UFPR), Brasil. b.fernando91@gmail.com

3 Mestranda em Ciência Política pela Universidade Federal do Paraná (UFPR), Brasil. s.brunatays@ gmail.com
} 
SOCIAL PROFIlE AND PARTY IDEOLOGY: AN ANALYSIS ON THE RECRUITMENT OF CITY COUNCILMEN CANDIDATES IN CURITIBA (2012)

\begin{abstract}
This article aims to investigate the role performed by ideology on the social composition of the applicants that disputed a seat to the Municipality of Curitiba, in the 2012 elections. In order to do so, it analyzes information declared by applicants for the Superior Electoral Court, namely, occupation, assets, education and gender. Our hypothesis herein is that parties have difficulties in assembling their lists of candidates in local elections and that this produces a greater level of heterogeneity on the social profile of the applicants, compared with the findings in the federal sphere. The data indicates that the municipal election has a distinct dynamics front of the federal election. It is more open to popular candidates with lower education level and non-traditional occupations.
\end{abstract}

Keywords: Political recruitment. Social profile. Ideology. 2012 Elections.

\title{
INTRODUÇÃo
}

Estudar o perfil social da elite política recrutada pelo sistema partidário é de suma importância para a compreensão de quem são os indivíduos à disposição do eleitorado. Por outro lado, a relação entre perfil social dos candidatos e a ideologia partidária revela o grau de coerência entre o discurso e a prática dos partidos políticos. Perissinotto e Miríade (2009), por exemplo, afirmam que somente conhecendo os atores disponíveis nas listas partidárias é possível afirmar que determinado grupo é prejudicado ou não consegue ascender a um cargo eletivo, já que muitas vezes tal grupo sequer consegue emplacar a candidatura de um representante.

Este artigo aborda a relação entre perfil social e ideologia partidária dos candidatos que disputaram o legislativo municipal de Curitiba, em 2012. O objetivo é compreender o papel da ideologia partidária e da influência que ela exerce sobre a composição social 
dos postulantes a um cargo eletivo. A hipótese do trabalho é que os partidos encontram dificuldades em compor suas listas no âmbito municipal e que isto produz uma heterogeneidade no perfil social dos candidatos. Tal dificuldade é sugerida pelo elevado número de candidatos (701) que concorrem às trinta e oito cadeiras da Câmara Municipal de Curitiba. Ou seja, esta escolha, por lançar uma vasta lista de nomes, faria com que houvesse uma diminuição da exigência qualitativa em relação ao perfil social dos candidatos, especialmente se compararmos esse perfil com o dos eleitos na esfera federal (COSTA; CODATO, 2013; RODRIGUES, 2002, 2009).

Ao invés de analisar os partidos de forma separada, eles serão analisados neste trabalho de maneira agregada, por blocos ideológicos. Por mais que seja possível argumentar que dentro de um bloco ideológico cada partido pode ter perfis sociais majoritários distintos, estudos brasileiros demonstram o contrário: a ideologia importa quando se trata de perfil social (COSTA; CODATO, 2013; RODRIGUES, 2002, 2009). Além disso, Tarouco e Madeira (2013) acreditam que analisar partidos agrupados conforme a ideologia a qual pertencem torna possível apontar para a atualidade da distinção entre esquerda e direita e ainda realizar um paralelo com estudos de outros países, verificando de que maneira são aproximáveis as atuações e composições de direita e esquerda mundo afora. A preocupação deste trabalho, no entanto, não é tão ambiciosa. Na sequência serão observadas e analisadas apenas as similaridades e distinções entre os perfis sociais encontrados para os diferentes blocos ideológicos em eleições federais e municipais.

Do ponto de vista metodológico, o trabalho é um estudo exploratório que analisa as variáveis ocupação, patrimônio, escolaridade e sexo dos candidatos em relação aos blocos ideológicos a qual pertencem, assim como fizeram Rodrigues $(2002,2009)$ e Costa e Codato (2013). Serão feitos testes estatísticos com a finalidade de 
indicar se as variáveis analisadas possuem relação umas com as outras, qual é a intensidade desta relação e em quais pares de categorias ela se dá. O universo estudado é comporto por todos os 701 candidatos a vereador pelo município de Curitiba que tiveram suas candidaturas deferidas pela Justiça Eleitoral nas eleições de 2012. As informações sobre o perfil social dos candidatos, como ocupação, patrimônio e escolaridade, foram extraídas do Repositório de Dados Eleitorais, do Tribunal Superior Eleitoral (BRASIL, 2012). Em relação à ideologia, além da distinção clássica entre direita, centro e esquerda, incluiu-se um grupo de partidos denominados de indefinidos ideologicamente. Esta escolha foi feita com base nas exíguas informações sobre o posicionamento destes pequenos partidos, baseando-se em Carreirão (2007).

A decisão de observar a disputa local tem o propósito de verificar se o recrutamento partidário nesta instância segue os mesmos padrões das disputas federais, onde a literatura sobre o tema indica que existe uma relação entre perfil social dos candidatos eleitos e a ideologia do seu partido. Por outro lado, os trabalhos dessa literatura se preocuparam até o momento em estudar apenas os parlamentares eleitos, deixando de lado o perfil dos candidatos que compõem a lista partidária. Neste trabalho consideraram-se todos os candidatos. Buscase assim enfatizar o papel desempenhado pelo partido no recrutamento de candidatos com determinado perfil social antes mesmo das escolhas promovidas pelos eleitores. Já a escolha de Curitiba se deve ao fato de o município possuir o maior distrito eleitoral do sul do país e o oitavo maior colégio eleitoral do Brasil, com pouco mais de 1,2 milhão de eleitores, segundo dados oficiais do Tribunal Superior Eleitoral. A escolha de Curitiba também é interessante porque a análise deste município pode ajudar a pensar as condições de recrutamento político em outras capitais brasileiras que não sejam São Paulo e Rio de Janeiro, que costumam mobilizar maior atenção por parte dos pesquisadores. 
$\mathrm{O}$ artigo divide-se em três partes. Na primeira, é discutida a literatura especializada sobre a importância e atualidade dos estudos de recrutamento político e composição social, assim como os resultados encontrados pelos estudos de casos que focalizaram o parlamento brasileiro. Em seguida, serão apresentados os achados desta pesquisa, observando ocupação, patrimônio, escolaridade e sexo dos candidatos frente ao posicionamento ideológico dos partidos. Por fim, nas considerações finais, é fornecido um breve resumo dos aspectos centrais deste trabalho, bem como suas limitações e algumas sugestões de pesquisas adicionais.

\section{ReVisão da Bibliografia}

O estudo de elites políticas e, em especial, o estudo das modalidades e formas do recrutamento dos quadros políticos, dentro da agenda investigativa da Ciência Política, oferece um ângulo analítico e uma metodologia muito fecunda para a compreensão de diversos fenômenos sociais e políticos. Disponibilizando, inclusive, importantes pontos de conceituação e uma estratégia metodológica que possibilita explicar de modo promissor variações nas estruturas e nos processos políticos (RODRIGUES, 2002; SANTOS 1997; SANTOS, 2000). Contudo, observa-se que os estudos sobre recrutamento no Brasil tendem a concentrar suas análises no perfil social dos que "chegaram lá", isto é, nos ocupantes dos postos mais importantes do sistema político brasileiro. Assim, esquece-se, muitas vezes, que o estudo sobre o recrutamento político objetiva, também, dar conta dos que estão tentando "chegar lá" (PERISSINOTTO; BOLOGNESI, 2009).

De um modo geral, o recrutamento refere-se a um processo de seleção dos socialmente favorecidos que atingem as posições de influência significativa (COSTA; CODATO, 2013). Deste modo, tornase importante diferenciar recrutamento e processo de seleção de 
lideranças. Enquanto o primeiro refere-se ao "modo como candidatos potenciais são atraídos para competir por um cargo político, [a] seleção é o processo pelo qual os candidatos são escolhidos a partir do pool de candidatos potenciais." (SIAVELIS; MORGESTERN, 2004 apud PERISSINOTTO; MIRÍADE, 2009, p. 322).

Buscando contribuir com o debate, Gaxie (2012) desenvolveu um estudo que aponta para a existência de uma determinada lógica social no processo do recrutamento político. De acordo com o autor, as particularidades do sucesso político se encontram inseridas dentro dos partidos políticos, ou seja, há uma lógica própria de concorrência interna, que de acordo com as características sociais das lideranças, pode opor-se à lógica seletiva dominante da competição política. Nesse sentido, as "lógicas do recrutamento político" (GAXIE, 2012) dos parlamentares aparecem com uma ordem invertida da estrutura social (pequenas representações dos estratos médios e populares e sobre representação das camadas altas). As diferenciações das bases sociais de recrutamento dos detentores de cargos, nos diferentes partidos, estariam, por sua vez, alicerçadas nas ligações privilegiadas de cada organização política com certas camadas sociais.

$\mathrm{Na}$ literatura sobre recrutamento parlamentar no Brasil, Rodrigues (2009) analisou as bases sócio-ocupacionais do Legislativo Federal (especificamente, as mudanças na composição sócioprofissional na Câmara dos Deputados decorrentes das eleições de 1998 e de 2002) para explicar determinadas mudanças no perfil da classe política brasileira em função da vitória do PT nas eleições para o Executivo Federal em 2002. O autor identificou uma queda de agentes de perfil mais elevado, sobretudo empresários, compensada por um aumento de agentes profissionais caracterizados como classe média. Houve também aumento dos deputados vindos das classes médias assalariadas e, em menor medida, das classes populares (RODRIGUES, 2009). 
Em outro estudo sobre a Câmara dos deputados, Braga, Veiga e Miríade (2009) examinou o processo de seleção dos candidatos a deputado federal realizado pelos partidos PP, PFL (DEM), PMDB, PSDB e PT, nas eleições de 2006, bem como o perfil social dos candidatos e dos eleitos. Buscou, com isto, demonstrar como as esferas locais e nacionais estão envolvidas na seleção de candidatos para o legislativo nacional. Por meio de uma avaliação das regras eleitorais e partidárias e de procedimentos informais identificados nas convenções partidárias realizadas no primeiro semestre de 2006, as autoras afirmam que existem diferenças entre os partidos com relação aos seus procedimentos de recrutamento. No entanto, estas diferenças diminuem após o processo eleitoral, apontando para um padrão mais uniforme entre os eleitos. Em suma, homens, com grau de escolaridade e patrimônio elevados, com carreira política ou médicos, advogados, engenheiros, empresários e funcionários públicos.

Dentro desta perspectiva, Álvares (2008) analisou os aspectos formais e informais que submetem candidatos a competir em uma eleição por meio dos estatutos partidários e demanda do partido (por exemplo, votos expressivos) e oferta de nome de filiados. A partir da aplicação de dois modelos, quais sejam, gatekeeper, de Norris Lovenduski, e selectorate, de Reuven Hazan, a autora investigou três partidos brasileiros (PT - PMDB - PP) com o objetivo de verificar o tipo formal de "selecionador" de candidatos sobre os filiados partidários e ainda sobre as candidaturas das mulheres no período de 1946 a 1982. Suas conclusões apontam que o "selecionador" não obedece a uma situação de gênero para dispor de suas regras e que a esquerda elegeu mais mulheres neste período.

Coradini (2012), por sua vez, abordando a relação entre recursos de posição social (ocupação e escolaridade), investimentos em campanhas e resultados eleitorais das diferentes esferas (municipais de 2004 e gerais de 2006), apresenta evidências de que há uma forte 
associação entre as categorias ocupacionais e titulação escolar e as chances de sucesso eleitoral. $\mathrm{O}$ autor aponta para uma tendência em que, na medida em que o cargo é hierarquicamente mais elevado, há uma concentração das categorias ocupacionais de posição social mais alta e de titulação escolar mais valorizada. O ponto positivo se expressa no modo pelo qual o autor atesta essas tendências, principalmente quando faz um cotejo do universo dos não-eleitos e eleitos e da distribuição conforme a posição político partidária dentro do espectro ideológico, confirmando a hipótese apresentada anteriormente.

Com relação ao âmbito municipal, Codato, Cervi e Perissinotto (2013) investigam o perfil de todos os candidatos a prefeitos nas eleições de 2012 e demonstram, a partir de um conjunto de variáveis (econômicas, sociais e políticas), que ser candidato à reeleição, fazer parte de uma coligação e estar em disputa por uma sigla de alto desempenho são os principais fatores que explicam o sucesso eleitoral. Ou seja, ser um "político profissional" foi o que garantiu maior êxito nas disputas municipais de 2012.

Dentro desta mesma expectativa, Perissinotto e Miríade (2009) observaram que as variáveis políticas são mais importantes para o sucesso eleitoral nos partidos de esquerda. Por meio de um estudo comparativo entre o perfil dos candidatos e eleitos a deputado federal nas eleições de 2006, analisaram as diferenças e semelhanças entre os partidos políticos de direita, centro e esquerda no que diz respeito a tais características: idade, sexo, ocupação, escolaridade e gastos com a campanha eleitoral. Os resultados apontam que algumas variáveis sociais são importantes para aumentar a chance de sucesso eleitoral, sobretudo a variável ocupação - empresários, produtores rurais, engenheiros, médicos e economistas são as ocupações com maior chance de sucesso. No caso dos deputados federais, as variáveis políticas foram mais relevantes para explicar sucesso eleitoral em todas 
as posições do espectro ideológico, com destaque para os partidos de esquerda.

Os autores Marenco dos Santos e Serna (2007), por sua vez, analisaram a composição e a trajetória da elite parlamentar no Brasil, Chile e Uruguai buscando identificar diferentes padrões de recrutamento partidário segundo os blocos ideológicos. Os autores identificam que, no Brasil, os partidos mais conservadores contemplam um número maior de agentes ligados ao mundo empresarial e que também estão vinculados à formação universitária de caráter liberal. Por outro lado, há um bloco mais diversificado, que aparece entre parlamentares de esquerda, que tem uma grande proporção de profissões vinculadas às classes médias - professores, profissionais da área de ciências humanas, funcionários públicos - e uma participação maior de assalariados e integrantes de camadas populares. De acordo com a trajetória dos políticos, a pesquisa aponta que os parlamentares de esquerda possuem padrões de filiação partidária definidas, carreiras políticas duradouras e acumulação de recursos políticos associativos e representativos.

Dentro desta mesma linha, Rodrigues (2002) tratou de demonstrar que o recrutamento das lideranças partidárias segue um padrão relacionado com características sócio/ocupacionais e ideológicas. De acordo com o autor, o padrão é significativo o suficiente para diferenciar os partidos tanto em termos ideológicos (esquerda, centro e direita) como em termos do perfil social predominante. Para tanto, o autor utilizou os resultados das eleições de 1990, 1994 e 1998 para a Câmara dos Deputados, além de dados biográficos dos deputados eleitos em 1998 (51ํㅡㄴ legislatura), e dados patrimoniais dos deputados segundo sua declaração de bens à receita federal. Deste modo, identificou que os partidos de direita comportam uma maior proporção de empresários e pessoas de alta renda entre seus deputados. Já nos partidos de esquerda há um maior número de deputados 
originários das classes médias e das classes trabalhadoras e populares. Por fim, nos partidos de centro, encontram-se, proporcionalmente, menos empresários e trabalhadores e mais parlamentares originários de outros estratos sociais intermediários, com patrimônio inferior aos dos partidos de direita e superior aos de esquerda (RODRIGUES, 2002). É importante destacar que o estudo de Rodrigues (2002) contribui não apenas por possibilitar uma definição detalhada da composição social das lideranças partidárias, mas também por abrir uma linha de pesquisa antes inexplorada, qual seja, o exame da documentação que os candidatos apresentam à Justiça Eleitoral quando registram sua candidatura.

Felisbino (2010), analisando o patrimônio dos políticos,

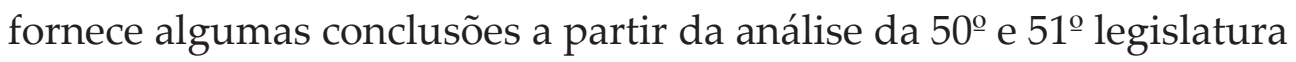
(1995 a 2002). Para estimular o debate acerca da importância da investigação sobre os bens patrimoniais dos parlamentares da Câmara dos Deputados, o autor levanta três pontos para reflexão. Em primeiro lugar, aponta que a maioria da elite analisada possui patrimônio inferior a 200 mil e que esses deputados se encontram principalmente nos partidos de esquerda. Além disso, o autor destaca que parlamentares pertencentes aos partidos de esquerda vêm progressivamente aumentando o patrimônio, sugerindo que o motivo possa ser a chegada do Partido dos Trabalhadores ao poder. Segundo, conclui que parlamentares de siglas partidárias do centro possuem patrimônio entre 500 mil e 2 milhões. E, por fim, destaca que ao longo dos anos de 1998 a 2006 observa-se um crescimento na soma dos patrimônios declarados pelos parlamentares dos partidos com maior representação dentro da Câmara dos Deputados (FELISBINO, 2010).

Como é possível observar, a maioria dos trabalhos realizados no Brasil optou por estudar apenas o perfil social dos eleitos para cargos de níveis federais. Este artigo busca contribuir para o preenchimento 
desta lacuna por meio de um estudo sobre a composição social dos candidatos a vereador na eleição de 2012, em Curitiba.

\section{Análises dos Perfis Sociais dos Candidatos}

Esta seção apresenta as características sociais dos candidatos de diferentes blocos partidários ideológicos em relação à ocupação, patrimônio declarado, escolaridade e sexo. A escolha por estas variáveis independentes deve-se a dois motivos principais. Primeiro, permite a comparação com os demais trabalhos produzidos sobre o tema, mas que tratam de parlamentares eleitos em eleições federais, como Rodrigues (2002, 2009), Costa e Codato (2013) e Felisbino (2010). Segundo, o estudo dessas variáveis permite utilizar apenas uma única fonte de dados oficiais, que é o Repositório de Dados Eleitorais, do Tribunal Superior Eleitoral (TSE). Dessa forma, pode-se trabalhar apenas com informações oficiais e declaradas pelos próprios candidatos, sem que os dados possam apresentar contradições com outras fontes.

A classificação ideológica dos partidos baseou-se na proposta de Figueiredo e Limongi (2001) e Souza e Cavalcante (2012). Além da separação clássica entre esquerda, centro e direita, também foi adicionada a categoria "indefinidos", proposta por Carreirão (2007) para alocar os partidos menores e que não dispõem de informações suficientes para sua classificação ideológica. Sendo assim, os partidos classificadosna esquerda foramPT,PCdoB,PSOL,PSTUePPL; nocentro estão PMDB, PSDB, PPS, PSB, PV e PDT; na direita foram incluídos DEM, PP, PSD, PTB, PSC, PSDC, PR, PRP e PRB; por fim, encontramse no grupo dos indefinidos PTC, PTdoB, PMN, PSL, PHS e PTN. A localização do PPS, PSB e PDT no centro, que contraria as convenções estabelecidas pelos estudos de ideologia partidária, incluindo os trabalhos de Figueiredo e Limongi (2001) e Souza e Cavalcante (2012), 
leva em conta a dinâmica destes partidos no município de Curitiba e as alianças eleitorais historicamente construídas por eles.

Em relação à análise dos dados, realizou-se uma análise descritiva baseada no total de pertencentes às categoriais e seus percentuais. Para medir a relação entre as variáveis, utilizaram-se três testes estatísticos: Qui-quadrado de Person, V de Cramer e os resíduos padronizados. O primeiro tem como objetivo indicar se a distribuição dos casos é independente (aleatória) ou dependente. Em outras palavras, é útil para indicar em quais relações testadas a distribuição dos casos sofre influência das variáveis. Quando o Quiquadrado indicar relação entre as variáveis, o V de Cramer é usado para indicar a intensidade da relação encontrada. Por fim, os resíduos padronizados são calculados para identificar onde se encontram as relações mais fortes entre as categorias e qual o sentido desta relação.

A primeira variável analisada é a ocupação declarada pelos candidatos. Para uma melhor visualização das informações, as ocupações foram agrupadas seguindo a classificação proposta por Rodrigues (2009). Devido ao baixo número de eclesiásticos (apenas 3), estes foram incluídos na categoria de comunicadores. $\mathrm{O}$ mesmo ocorre com os intelectuais (9), que foram alocados junto aos profissionais liberais.

Na Tabela 1, é possível visualizar as ocupações declaradas pelos candidatos em vista da ideologia ao qual seu partido pertence. Ao contrário do que ocorre em nível federal entre eleitos, seja na Câmara dos Deputados (RODRIGUES, 2002, 2009) ou no Senado Federal (COSTA; CODATO, 2013), no âmbito municipal é possível encontrar um predomínio de candidatos provenientes de trabalhadores urbanos ${ }^{4}$ (35,7\% dos candidatos, ao todo). Como o número de candidatos pertencentes a esta categoria é muito elevado, próximo ao dobro da segunda, para quase todos os posicionamentos ideológicos há maior

Neste grupo, foram incluídos todos os indivíduos que declararam como profissão àquelas que não se enquadram nas demais. É composto sobretudo por profissionais pertencentes a ocupações com menor exigência técnica. 
número de trabalhadores urbanos do que entre demais ocupações, a exceção é entre os partidos de centro. Em seguida, aparecem os empresários e os profissionais liberais, que representaram 20,7\% e $17,5 \%$ dos candidatos, respectivamente. Na análise nacional para à Câmara e o Senado, são estas as duas profissões dominantes.

Tabela 1 - Ocupações e ideologia partidária

\begin{tabular}{|c|c|c|c|c|c|c|}
\hline \multicolumn{2}{|l|}{ Ocupação } & Esquerda & Centro & Direita & Indefinidos & $\%$ total $(\mathrm{N}$ \\
\hline \multirow{2}{*}{$\begin{array}{l}\text { Trabalhador } \\
\text { urbano }\end{array}$} & $\%$ & 35,2 & 22,8 & 38,4 & 47,4 & \multirow{2}{*}{$35,7(250)$} \\
\hline & R.P. & $-0,06$ & $-2,97^{*}$ & 0,82 & $2,28^{*}$ & \\
\hline \multirow{2}{*}{$\begin{array}{l}\text { Empresário/ } \\
\text { comerciante }\end{array}$} & $\%$ & 3,7 & 23,3 & 19,8 & 25,9 & \multirow{2}{*}{$20,7(145)$} \\
\hline & R.P. & $-2,74^{*}$ & 0,78 & $-0,34$ & 1,34 & \\
\hline \multirow{2}{*}{$\begin{array}{l}\text { Profissional } \\
\text { liberal/ } \\
\text { intelectual }\end{array}$} & $\%$ & 27,8 & 20,6 & 17,0 & 10,4 & \multirow{2}{*}{$17,5(123)$} \\
\hline & R.P. & 1,79 & 1,01 & $-0,22$ & $-1,99 *$ & \\
\hline \multirow{2}{*}{$\begin{array}{l}\text { Funcionário } \\
\text { público }\end{array}$} & $\%$ & 9,3 & 11,1 & 8,7 & 7,4 & \multirow{2}{*}{$9,1(64)$} \\
\hline & R.P. & 0,03 & 0,90 & $-0,27$ & $-0,66$ & \\
\hline \multirow{2}{*}{ Magistério } & $\%$ & 22,2 & 10,1 & 5,6 & 1,5 & \multirow{2}{*}{$7,3(51)$} \\
\hline & R.P. & $4,07^{*}$ & 1,42 & $-1,13$ & $-2,50^{*}$ & \\
\hline \multirow{2}{*}{$\begin{array}{l}\text { Comunicador/ } \\
\text { eclesiástico }\end{array}$} & $\%$ & 1,9 & 3,7 & 5,6 & 5,2 & \multirow{2}{*}{$4,7(33)$} \\
\hline & R.P. & $-0,97$ & $-0,64$ & 0,72 & 0,26 & \\
\hline \multirow{2}{*}{ Aposentado } & $\%$ & 0,0 & 5,3 & 3,1 & 1,5 & \multirow{2}{*}{$3,1(22)$} \\
\hline & R.P. & $-1,30$ & 1,67 & $-0,04$ & $-1,09$ & \\
\hline \multirow{2}{*}{ Político } & $\%$ & 0,0 & 3,2 & 1,9 & 0,7 & \multirow{2}{*}{$1,9(13)$} \\
\hline & R.P. & $-1,00$ & 1,33 & 0,00 & $-0,95$ & \\
\hline Total & $\%(N)$ & $100(54)$ & $\begin{array}{c}100 \\
(189)\end{array}$ & $\begin{array}{c}100 \\
(323)\end{array}$ & $100(135)$ & $100(701)$ \\
\hline \multicolumn{7}{|c|}{ Qui-quadrado: $71,746(0,000)$} \\
\hline \multicolumn{7}{|c|}{ V de Cramer: 0,185 $(0,000)$} \\
\hline
\end{tabular}

Fonte: Os autores, com base nas declarações dos candidatos ao TSE.

*Resíduos Padronizados (R.P.) com significância estatística. 
Ao observar a composição ocupacional dos blocos ideológicos, observa-se que há na esquerda uma maior concentração de trabalhadores urbanos, profissionais liberais e do magistério. O centro, por sua vez, comporta mais empresários/comerciantes, trabalhadores urbanos e profissionais liberais em seus quadros. Já na direita, assim como entre os chamados partidos indefinidos, há um amplo domínio de trabalhadores urbanos, seguidos de empresários. O teste do Qui-quadrado de Person apresentou uma significância de 0,000 para um intervalo de confiança de $95 \%$. Isto quer dizer que a distribuição dos casos não é aleatória ou próxima a esperada e que, portanto, as variáveis estão relacionadas. O V de Cramer de 0,185 pode ser interpretado como uma relação de 18,5\% entre as ocupações declaradas pelos candidatos e a ideologia dos seus partidos. Assim, as variáveis apresentam dependência estatística, entretanto, ela é baixa. A análise dos resíduos padronizados (R.P.), por sua vez, indica que os valores positivos com asterisco possuem uma concentração de casos acima do esperado, ao passo que os valores negativos com asterisco possuem uma representação menor do que a esperada ${ }^{5}$.

Os dados acima permitem afirmar que as ocupações dos partidos de esquerda seguem os padrões já encontrados anteriormente pela literatura em relação aos eleitos para a Câmara e para o Senado, já que há uma alta e significativa representação de indivíduos empregados no magistério e uma quantidade pequena de empresários/ comerciantes. Neste sentido, os dados reforçam os achados de Rodrigues $(2002,2009)$ e Costa e Codato (2013). Mesmo quando se analisa a disputa municipal, os partidos de esquerda continuam sendo ocupados majoritariamente por professores e profissionais liberais. Já

\footnotetext{
Na análise dos resíduos padronizados, a um intervalo de confiança de 95\%, podem ser considerados significativos os resíduos superiores a $\pm 1,96$. Ou seja, quando os valores são superiores a $+1,96$ é possível afirmar que aquele par de categorias possui uma concentração acima da esperada de casos. Por outro lado, sendo o valor superior a -1,96, há uma representação menor do que à esperada.
} 
a baixa representação de empresários pode estar ligada justamente às bandeiras trabalhistas historicamente defendidas pela esquerda. $\mathrm{O}$ centro, por sua vez, apresenta um único resíduo significativo, que é negativo para trabalhadores urbanos. Apesar de difícil comparação para outras esferas, já que elas apresentam uma quantidade muito reduzida de indivíduos com esta ocupação, são justamente os partidos deste posicionamento que não possuíam nenhum trabalhador urbano eleito na Câmara em 2002 e 2006 e apenas um senador na série histórica de 1986 a 2010 (COSTA; CODATO, 2013; RODRIGUES, 2002, 2009). Ademais, como já apontado, é também no centro que os trabalhadores urbanos ocupam o menor percentual de candidatos, comparado aos demais blocos ideológicos. Esta informação, somada à grande quantidade de empresários e profissionais liberais, parece indicar que os partidos de centro se interessam por indivíduos com profissões mais flexíveis, que permitem a dedicação do candidato ao pleito.

Dentre os partidos indefinidos ideologicamente, há uma grande concentração de trabalhadores urbanos (resíduo positivo e significativo, com quase metade dos candidatos se autodeclarando desta categoria). Por outro lado, apresentam uma sub-representação de profissionais liberais e do magistério. Estas informações, tomadas em conjunto, podem denotar que estes partidos menores têm pouca atratividade para estes profissionais. Entretanto, atrai a atenção de empresários, que representam um quarto dos candidatos, que teriam maior liberdade de atuação em partidos menos estabelecidos, e de profissionais urbanos por conta de uma possível dificuldade de compor as listas partidárias com outros perfis. Por fim, entre os partidos de direita nenhum resíduo foi significativo. Os empresários, tão presentes na Câmara e Senado, não são maioria e estão quase igualados em representatividade com profissionais liberais. Possivelmente isto se deve ao fato de que os empresários da direita almejam cargos políticos de maior poder, como é o legislativo estadual e federal. 
Até o momento, este artigo tratou das ocupações declaradas pelos candidatos em relação à posição ocupada no espectro ideológico pelos partidos. A seguir, a análise focaliza os patrimônios declarados pelos candidatos. Mas antes é preciso ponderar que essa análise é prejudicada pelo baixo número de candidatos que apresentaram à Justiça Eleitoral sua declaração de patrimônio: somente 349 dos 701 candidatos, ou seja, 49,8\%. Mas, sobretudo, pela enorme variação entre o maior $(R \$ 10.181 .059,00)$ e o menor $(R \$ 250,00)$ valor declarado por parte dos candidatos. Diante disso, optou-se por eliminar os outliers, por meio do cálculo de determinação destes, e promover uma categorização dos patrimônios a partir da fórmula de Sturges. Assim, chegou-se às seguintes faixas patrimoniais dos candidatos: até $\mathrm{R} \$ 90.501$, baixo; até $\mathrm{R} \$ 180.753$, médio-baixo; até $\mathrm{R} \$ 271.005$, médio; até $\mathrm{R} \$ 361.257$, médio-alto; e, por fim, até $\mathrm{R} \$ 406.383$, alto. Candidatos que declararam patrimônio superior à faixa "alto" foram considerados outliers e, portanto, excluídos da análise ${ }^{6}$.

A tabela 2 cruza o patrimônio declarado pelos candidatos e a ideologia de seus partidos. É possível observar que mais de 70\% dos candidatos analisados concentram-se nas duas faixas mais baixas de patrimônio, o que faz com que todos os blocos ideológicos concentrem maior quantidade de candidatos nestas categorias. O teste do Quiquadrado de Person apresentou significância de 0,476 (acima do limite crítico de 0,050 para um intervalo de confiança de 95\%), indicando que a distribuição dos casos se deu de maneira independente. Em outras palavras, a distribuição é normal, não havendo dependência entre as variáveis. Diante disso, não foram testados o V de Cramer e de resíduos padronizados, já que os valores não seriam significativos.

Dos 69 outliers, 5 pertenciam a partidos de esquerda, 37 ao centro, 25 à direita e 2 aos indefinidos. 
Tabela 2 - Patrimônio Declarado E Ideologia Partidária

\begin{tabular}{|c|c|c|c|c|c|c|}
\hline \multicolumn{2}{|c|}{ Patrimônio } & \multirow{2}{*}{$\begin{array}{c}\text { Esquerda } \\
48,4\end{array}$} & \multirow{2}{*}{$\begin{array}{c}\text { Centro } \\
41,3\end{array}$} & \multirow{2}{*}{$\begin{array}{l}\text { Direita } \\
\text { 50,8 }\end{array}$} & \multirow{2}{*}{$\begin{array}{c}\text { Indefinidos } \\
60,0\end{array}$} & \multirow{2}{*}{$\begin{array}{c}\text { \% total } \\
(\mathrm{N}) \\
47,5 \\
(133)\end{array}$} \\
\hline $\begin{array}{l}\text { Muito } \\
\text { baixo }\end{array}$ & $\%$ & & & & & \\
\hline Baixo & $\%$ & 22,6 & 28,8 & 23,8 & 20,0 & $\begin{array}{l}25,4 \\
(71)\end{array}$ \\
\hline Médio & $\%$ & 6,5 & 11,5 & 12,3 & 20,0 & $\begin{array}{l}11,8 \\
(33)\end{array}$ \\
\hline Alto & $\%$ & 16,1 & 13,5 & 12,3 & 0,0 & $\begin{array}{l}12,5 \\
(35)\end{array}$ \\
\hline $\begin{array}{l}\text { Muito } \\
\text { alto }\end{array}$ & $\%$ & 6,5 & 4,8 & 0,8 & 0,0 & $2,9(8)$ \\
\hline Total & $\%(N)$ & $100(31)$ & $100(104)$ & $100(130)$ & 100 (15) & $\begin{array}{c}100 \\
(280)\end{array}$ \\
\hline
\end{tabular}

Qui-quadrado: 11,624 (0,476)

Fonte: Os autores, com base nas declarações dos candidatos ao TSE.

Em âmbito federal, Rodrigues (2002) e Felisbino (2010) apontam para um predomínio de parlamentares com médio-alto e alto patrimônio em partidos de direita e centro, enquanto que a esquerda é representada predominantemente por deputados com baixo e médio-baixo patrimônio. Na presente pesquisa, a esquerda possui um percentual pouco acentuado, mas superior aos demais blocos, de indivíduos presentes nas faixas "alta" e "muito alta". Os indefinidos, por sua vez, não tiveram nenhum candidato que declarou bens superiores à faixa média. Entretanto, há de salientar que este foi o grupo com menor percentual de postulantes que apresentou declaração de bens. Dos 135 candidatos destes partidos, apenas 17 (contando com os outliers) tinham bens declarados. Uma hipótese para este fato é de que estes partidos, por serem menores e menos enraizados, não exercem forte controle sobre os seus quadros, o que desincentiva o cumprimento das práticas eleitorais.

Os dados de patrimônio, como já foi dito, trouxeram problemas para a análise, que inviabilizaram melhores conclusões. Portanto, há 
de ter cuidado com inferências sobre eles. Acredita-se que o baixo número de candidatos com declaração de bens se deve, sobretudo, a permissividade da legislação. A Lei da Eleições (Lei 9.504/97), que prevê a declaração dos bens dos candidatos, não institui qualquer punição ao candidato que não a fizer. Também, ao contrário das normas que regulamentam as doações eleitorais aos candidatos, por exemplo, ela não contrapõe estas declarações de bens ao declarado pelo candidato em seu Imposto de Renda. Assim, estes dados que são disponibilizados podem ser também subestimados pelos candidatos.

A tabela seguinte sumariza as informações a respeito dos diferentes níveis de escolaridade declarados pelos candidatos em relação à ideologia dos partidos aos quais eles pertencem. Assim como na Câmara dos Deputados (RODRIGUES, 2009), há um predomínio de candidatos com ensino superior completo $(41,7 \%)$ e ensino médio completo $(27 \%)$. Contudo, estes números de ensino superior em candidatos a vereador são muito inferiores dos presentes para os eleitos na Câmara. Rodrigues (2009) aponta que 82,2\% dos eleitos em 1998 tinham ensino superior, enquanto que em 2002, 76,9\% tinham este perfil. A eleição municipal é, portanto, mais popular, tanto do ponto de vista educacional quanto ocupacional.

Tabela 3 - Escolaridade e Ideologia Partidária

\begin{tabular}{|c|c|c|c|c|c|c|}
\hline Escolaridade & & Esquerda & Centro & Direita & Indefinidos & $\%$ total $(\mathrm{N})$ \\
\hline $\begin{array}{l}\text { Ensino } \\
\text { Fundamental } \\
\text { incompleto }\end{array}$ & $\begin{array}{c}\% \\
\text { R.P. }\end{array}$ & $\begin{array}{l}0,0 \% \\
-1,64\end{array}$ & $\begin{array}{l}2,6 \% \\
-1,44\end{array}$ & $\begin{array}{l}3,1 \% \\
-1,53\end{array}$ & $\begin{array}{l}14,8 \% \\
5,11^{*}\end{array}$ & $5,0(35)$ \\
\hline $\begin{array}{l}\text { Ensino } \\
\text { Fundamental } \\
\text { completo }\end{array}$ & $\begin{array}{c}\% \\
\text { R.P. }\end{array}$ & $\begin{array}{l}1,9 \% \\
-1,38\end{array}$ & $\begin{array}{l}9,5 \% \\
1,50\end{array}$ & $\begin{array}{r}6,2 \% \\
-0,36\end{array}$ & $\begin{array}{r}5,9 \% \\
-0,35\end{array}$ & $6,7(47)$ \\
\hline $\begin{array}{l}\text { Ensino Médio } \\
\text { incompleto }\end{array}$ & $\begin{array}{c}\% \\
\text { R.P. }\end{array}$ & $\begin{array}{r}0,0 \% \\
-1,76\end{array}$ & $\begin{array}{c}0,5 \% \\
-2,98^{*}\end{array}$ & $\begin{array}{l}7,7 \% \\
1,53\end{array}$ & $\begin{array}{l}10,4 \% \\
2,27 *\end{array}$ & $5,7(40)$ \\
\hline
\end{tabular}


continuação

\begin{tabular}{l|c|c|c|c|c|c} 
Ensino Médio & $\%$ & $14,8 \%$ & $20,1 \%$ & $30,3 \%$ & $33,3 \%$ & $27(189)$ \\
completo & R.P. & $-1,72$ & $-1,82$ & 1,17 & 1,43 & \\
Ensino Superior & $\%$ & $13,0 \%$ & $15,9 \%$ & $14,2 \%$ & $11,1 \%$ & $14(98)$ \\
incompleto & R.P. & $-0,20$ & 0,70 & 0,13 & $-0,89$ & \\
Ensino Superior & $\%$ & $70,4 \%$ & $51,3 \%$ & $38,4 \%$ & $24,4 \%$ & $41,7(292)$ \\
completo & R.P. & $3,27 *$ & $2,06 *$ & $-0,91$ & $-3,10 *$ & \\
\cline { 1 - 1 } Total & $\%$ & $100(54)$ & 100 & 100 & $100(135)$ & $100(701)$ \\
\hline
\end{tabular}

Qui-quadrado: $93,369(0,000)$

V de Cramer: 0,211 (0,000)

Fonte: Os autores, com base nas declarações dos candidatos ao TSE.

* Resíduos Padronizados (R.P.) com significância estatística.

O teste do Qui-quadrado de Person resultou em 0,000 de significância. Desta forma, é possível afirmar que as variáveis "escolaridade" e "ideologia partidária" estão relacionadas, havendo dependência entre elas na distribuição dos casos. Já o V de Cramer aponta para uma baixa relação entre as variáveis, de apenas 21,1\%.

Em relação à representação por ideologia, com exceção dos indefinidos, todos os demais tiveram o maior percentual para candidatos com formação superior. Dentre os candidatos de esquerda, apenas 1,9\% deles não têm ensino médio completo, fato este que sugere uma exigência maior destes partidos, ao menos em termos de escolaridade, para participar das eleições. A confirmação é encontrada por meio da alta concentração de candidatos com ensino superior e pertencentes a partidos de esquerda, indicada pelos resíduos padronizados. Desta forma, a chance de um candidato com pouca instrução escolar conseguir concorrer por um destes partidos é mínima. Para os partidos de centro, apesar da mudança de percentuais em vista da esquerda, são também os indivíduos com ao menos formação média concluída que predominam. Os resíduos 
mostram baixa representação de escolaridade média incompleta, sendo compensada por uma concentração de casos em ensino superior completo. É possível concluir, portanto, que em se tratando de centro e esquerda, até mesmo em uma eleição que não é tão atrativa em termos de prestígio e poder, prevalecem os indivíduos mais escolarizados.

Já os candidatos de direita, como apontam os resíduos padronizados, têm uma distribuição próxima da esperada para todas as categorias de escolaridade. Isto não significa que em percentuais a distribuição é semelhante, mas sim que não há concentração positiva ou negativa de casos, segundo o teste estatístico. Assim como para todos os outros grupos, o maior percentual de indivíduos está a partir de ensino médio completo. Entretanto, há na direita mais espaço do que na esquerda e centro para candidatos com menos permanência escolar. Isto reforça a hipótese de que os principais quadros de direita possuem menor interesse pela disputa legislativa municipal, já que a ocupação e a escolaridade diferem em muito das apresentadas pelos eleitos para à Câmara dos Deputados, por exemplo. Por fim, os indefinidos apresentam um padrão bastante característico em vista dos seus adversários, já que é o grupo com maior percentual e concentração positiva de casos com ensino fundamental e médio incompleto. Por outro lado, têm o menor percentual de concorrentes com ensino superior completo e o resíduo padronizado é negativo e estatisticamente significativo. Mais uma vez é possível defender que estes partidos são pouco atrativos para os candidatos, o que faria com que a necessidade de compor as listas reduzisse as barreiras a um perfil mais popular de indivíduos.

Dentre os achados de Rodrigues (2002, 2009), quando este estudou os eleitos à Câmara dos Deputados em 1998 e 2002 pelos principais partidos brasileiros, está a relativa homogeneidade entre os níveis de escolaridade e a ideologia dos partidos. O fato é que, naquele caso, cerca de $80 \%$ dos parlamentares possuíam nível superior. Desta 
forma, a diferença entre esquerda, centro e direita referia-se à formação profissional dos eleitos e não em grau de escolaridade. Como mostrouse acima, a eleição municipal de 2012 em Curitiba apresentou outro quadro: a ideologia esteve relacionada com o nível de escolaridade dos candidatos. Assim, era mais provável encontrar um candidato com formação superior em partidos de esquerda do que na direita, ao passo que os candidatos com baixa escolaridade (até ensino médio incompleto) estiveram mais presentes na direita do que na esquerda.

A sequência do artigo versa sobre a representação de homens e mulheres entre os candidatos dos quatro grupos ideológicos. Através da lei 12.034/09, institui-se no Brasil a obrigatoriedade de que os partidos destinem ao menos 30\% de suas listas a um dos sexos, como forma de tentar aumentar a participação feminina na política. Desta forma, era de se esperar que ao menos esta representação mínima seria respeitada na indicação dos candidatos. Contudo, talvez em razão da falta de um mecanismo punitivo aos partidos que não cumprem tal lei, nota-se que ela não foi totalmente aceita e respeitada ainda.

A tabela 4 nos mostra que, em universo de 701 candidatos a vereador, apenas 192 eram mulheres (o que representa 27,39\% do total), ou seja, de fato alguns partidos não respeitaram a legislação eleitoral que os obriga a destinar um mínimo de 30\% de sua lista a um dos sexos. Os dados mostram que a trajetória da esquerda à direita e indefinidos leva a uma perda de espaço das mulheres nestes partidos, já que apenas os partidos à esquerda do espectro ideológico destinam um espaço superior a 30\% para elas. Ressalta-se, todavia, que o teste do Qui-quadrado, com significância de 0,595, não aponta para dependência entre as variáveis, ou seja, não existem diferenças estatisticamente significativas entre as distribuições dos casos. 
Tabela 4 - Sexo e ideologia partidária

\begin{tabular}{l|c|c|c|c|c|c}
\hline Sexo & & Esquerda & Centro & Direita & Indefinidos & $\%$ total (N) \\
\hline Masculino & $\%$ & $64,8 \%$ & $72,5 \%$ & $73,4 \%$ & $74,1 \%$ & $72,6(509)$ \\
\hline Feminino & $\%$ & $35,2 \%$ & $27,5 \%$ & $26,6 \%$ & $25,9 \%$ & $27,4(192)$ \\
\hline Total & $\%(\mathrm{~N})$ & $100(54)$ & $\begin{array}{c}100 \\
(189)\end{array}$ & $\begin{array}{c}100 \\
(323)\end{array}$ & $100(135)$ & $100(701)$ \\
\hline
\end{tabular}

Qui-quadrado: 1,892 (0,595)

Fonte: Os autores, com base nas declarações dos candidatos ao TSE.

Com base nestes dados apresentados, sugere-se que as mulheres têm melhores possibilidades de serem aceitas candidatas por um partido de esquerda do que pelos demais. Nota-se também que os partidos indefinidos são os que ofertam menores oportunidades às mulheres. Contudo, não podemos afirmar categoricamente que este fenômeno ocorre sem antes estudar a seleção de candidatos nestes partidos com base na oferta de candidatas e a demanda dos partidos, ou seja, os interesses ou características procuradas quando da seleção (NORRIS, 1997).

\section{Considerações Finais}

A partir da pesquisa realizada, tentou-se estabelecer os perfis sociais mais presentes entre partidos de esquerda, direita e centro nas eleições municipais de Curitiba, em 2012. Ao longo do texto estes números foram comparados com a composição social dos partidos em nível nacional, já que são poucos os artigos que se destacam por operacionalizar esta relação em eleições municipais. Desta forma, pouco se sabe a respeito do funcionamento e recrutamento partidário em nível local, ao passo que alguns autores já focalizaram ideologia e perfil social em âmbito federal (COSTA; CODATO, 2013; RODRIGUES, 2002, 2009). Parece claro que um estudo ampliado, longitudinal e com 
um número maior de municípios produziria conclusões mais relevantes e definitivas. Todavia, este esforço inicial pretendeu dar mostras de que este é um tema controverso (em comparação com os estudos federais) e que merece mais atenção por parte dos pesquisadores.

Em relação as ocupações dos candidatos, viu-se que a diferença central entre legislativo municipal e federal está na quantidade elevada de trabalhadores urbanos presentes na corrida pelo cargo de vereador. Neste sentido, outro dado que chamou atenção foi a quantidade reduzida de empresário entre as agremiações de direita se comparado com a esfera federal. Especula-se que isto se deve a um interesse da classe por cargos eletivos de maior poder e prestígio, como é o de deputado federal e senador da república. Já para a variável patrimônio dos candidatos, a análise foi prejudica pelo baixo número de indivíduos que declararam bens e à alta variação nos valores declarados. Sugerese também que alguns deles possam estar subestimados, visto que a legislação não oferece punição e não exerce qualquer controle efetivo sobre a veracidade das informações, ao contrário do que acontece com o financiamento eleitoral, por exemplo.

A escolaridade dos candidatos também apresentou diferenças entre eleição municipal e federal. Apesar dos indivíduos com ensino superior completo serem maioria, este valor é inferior ao encontrado no âmbito federal. Isto reforça a ideia de que a disputa municipal é mais permeável para os diferentes perfis sociais, mas não descarta uma agenda de pesquisa de seleção de candidatos para verificar o tipo de demanda recebida pelos partidos. Finalmente, ao observar a distribuição de mulheres e homens dentro do espectro ideológico, verifica-se maior representatividade feminina entre os partidos de esquerda. Tendo em vista que uma das bandeiras atuais de alguns partidos de esquerda é justamente a redução das desigualdades de gênero, este número não é surpreendente. Entretanto, o percentual 
total de mulheres concorrendo ao pleito, de $27 \%$, está aquém ainda do que se espera em uma sociedade predominantemente feminina.

Como sugestão para trabalhos futuros, o processo de seleção dos candidatos é algo que pode ser melhor explorado. Somente através da análise de recrutamento em eleições municipais, como a que foi feita por este trabalho, não é possível afirmar se o perfil dos candidatos está mais ligado a uma questão de oferta de indivíduos ou de demanda dos partidos por perfis específicos. Tendo em vista algumas diferenças entre a composição social de candidatos a vereador e eleitos para o Senado Federal e a Câmara dos Deputados, parece haver nas eleições municipais uma dificuldade dos partidos em recrutar candidatos. Com isto, os partidos podem acabar adotando critérios mais brandos para a composição de suas listas do que em eleições federais. Uma hipótese alternativa é de que há menor interesse dos indivíduos ligados ao empresariado ou de maior escolaridade, por exemplo, nestas disputas e que isto explicaria a diferença entre quem se elege deputado e quem apenas concorre no legislativo municipal.

\section{REFERÊNCIAS}

ÁLVARES, Maria Luzia Miranda. Mulheres brasileiras em tempo de competição eleitoral: seleção de candidaturas e degraus de acesso aos cargos parlamentares. Dados, Rio de Janeiro, v. 51, n. 4, p. 895-939, 2008.

BRAGA, Maria do Socorro Sousa; VEIGA, Luciana Fernandes; MIRÍADE, Angel. Recrutamento e perfil dos candidatos e dos eleitos à Câmara dos Deputados nas eleições de 2006. Revista Brasileira de Ciências Sociais, São Paulo, v. 24, n. 70, jun. 2009.

BRASIL. Tribunal Superior Regional. Repositório de dados eleitorais. Disponível em: <http://www.tse.jus.br/eleicoes/estatisticas/repositorio-de-dados-eleitorais>. Acesso em:7 nov. 2012.

CARREIRÃO, Yan de Souza. Identificação ideológica, partidos e voto na eleição presidencial de 2006. Revista Opinião Pública, Bauru, v. 13, n. 2, p. 307-339, 2007. 
CODATO, Adriano N.; CERVI, Emerson U.; PERISSINOTTO, Renato M. Quem se elege prefeito no Brasil? Condicionantes do sucesso eleitoral em 2012. Cadernos Adenauer, Rio de Janeiro, ano XIV, n. 2, 2013.

CORADINI, Odaci Luiz. Categorias sócio-profissionais, titulação escolar e disputas eleitorais. Revista de Sociologia e Política, Curitiba, v. 20, n. 41, fev. 2012.

COSTA, Luiz Domingos; CODATO, Adriano N. Profissionalização ou popularização da classe política brasileira? Um perfil dos senadores da república. In: SANTOS, Andre Marenco dos (Org.). Os eleitos: representação e carreiras políticas em democracias. Porto Alegre: Ed. UFRGS, 2013.

FELISBINO, Riberti Almeida. Políticos do Brasil: partidos e patrimônio na Câmara dos Deputados (1995-2002). Acta Scientiarum. Human and Social Sciences, Maringa, v. 32, n. 1, p. 21-30, 2010.

FIGUEIREDO, Argelina Cheibub; LIMONGI, Fernando. Executivo e legislativo na nova ordem constitucional. Rio de Janeiro: Ed. FGV, 2001.

GAXIE, Daniel. As lógicas do recrutamento político. Revista Brasileira de Ciência Política, Brasília, n. 8, p. 165-208, 2012.

NORRIS, Pippa. Passages to power: legislative recruitment in advanced democracies. Cambridge: Cambridge University Press. 1997.

PERISSINOTTO, Renato M.; BOLOGNESI, Bruno. O recrutamento político no PTPT e no PFL paranaenses nas eleições de 2006: sugestões de pesquisa. Mediações, Londrina, v. 14, n.1, p. 143-169, jan./jun. 2009.

PERISSINOTTO, Renato M.; MIRÍADE, Angel. Caminhos para o parlamento: candidatos e eleitos nas eleições para deputado federal em 2006. Dados, Rio de Janeiro, v. 52, n. 2, p. 301-333, 2009.

RODRIGUES, Leôncio M. Mudanças na classe política brasileira. Rio de janeiro: Centro Edelstein de Pesquisas Sociais, 2009.

RODRIGUES, Leôncio M. Partidos, ideologia e composição social. São Paulo: Edusp, 2002.

SANTOS, Andre Marenco dos. Nas fronteiras do campo político: raposas e outsiders no Congresso Nacional. Revista Brasileira de Ciências Sociais, São Paulo, v. 12, n. 33, 1997.

SANTOS, Andre Marenco dos; SERNA, Miguel. Por que carreiras políticas na esquerda e na direita não são iguais? Recrutamento legislativo em Brasil, Chile e Uruguai. Revista Brasileira de Ciências Sociais, São Paulo, v. 22, n. 64, p. 93-113, jun. 2007. 
SANTOS, Fabiano. Deputados Federais e Instituições Legislativas no Brasil: 194699. In: SANTOS, Fabiano. Elites políticas e econômicas no Brasil. São Paulo: Fundação Konrad Adenauer, 2000.

SOUZA, Carlos Augusto da Silva; CAVALCANTE, Maria Jeane da Silva. Padrões geográficos das coligações eleitorais no Brasil: uma análise pela perspectiva ideológica dos partidos políticos - 2002 e 2006. In: ENCONTRO ANUAL DA ANPOCS, 36., 2012, Águas de Lindóia. Anais... Águas de Lindoía, 2012. Disponível em: $<$ http://www.anpocs.org/portal/ index.php?option=com_docman\&task=doc_ view\&gid=8123\&Itemid=76>. Acesso em: 13 maio 2014 .

TAROUCO, Gabriela da Silva; MADEIRA, Rafael Machado. Partidos, programas e o debate sobre esquerda e direita no Brasil. Revista de Sociologia e Política, Curitiba, v. 21, n. 45, p. 149-165, mar. 2013. 